\title{
Lixiviação de íons após a aplicação de resíduos orgânicos de uma indústria farmoquímica
}

\author{
Augusto V. Luchese ${ }^{1}$, Antonio C. S. da Costa $^{2}$ \& Ivan G. Souza Júnior ${ }^{1}$
}

\begin{abstract}
RESUMO
Nas últimas décadas, quantidades crescentes de resíduo industrial têm sido depositadas sobre o solo, de forma planejada ou acidental, razão pela qual se objetiva avaliar neste trabalho, o impacto da aplicação de uma dose alta de resíduos orgânicos (Biossólido - Bs e Lodo - Lo), produzidos por indústria farmoquímica, na contaminação dos mananciais de água; para tanto, montou-se um experimento em coluna de PVC de $20 \times 120 \mathrm{~cm}$ (diâmetro x altura) em um fatorial $2 \times 2 \times 2+2$, sendo 2 solos (NVdf e PVd), 2 resíduos (Bs e Lo), 2 formas de aplicação de 1 milhão de L ha-1 (incorporado e em superfície) e 1 testemunha para cada solo; em cada coluna foram feitas 10 aplicações de água correspondentes a $120 \%$ da capacidade de retenção de água das colunas e coletados os efluentes para avaliação dos seus atributos químicos. A condutividade elétrica (CE) do lixiviado apresentou grande diminuição da $1^{\mathrm{a}}$ para a $2^{\mathrm{a}}$ aplicação de água e o pH aumentou até a quarta aplicação de água. Os íons apresentaram comportamentos diferentes pois aqueles que formam complexos de esfera externa $\left(\mathrm{NO}_{3}{ }^{-}, \mathrm{Cl}, \mathrm{Ca}^{2+}, \mathrm{Mg}^{2+} \mathrm{e} \mathrm{Na}^{+}\right)$indicaram rápida lixiviação. Os nutrientes que formam complexos de esfera interna se comportaram de maneira diferente, sendo que $\mathrm{PO}_{4}{ }^{3-}$ apresentou baixa lixiviação, $\mathrm{K}^{+}$ lixiviou menos que nos tratamentos testemunhas e $\mathrm{SO}_{4}{ }^{2-}$ lixiviou mais a partir da $3^{\text {a }}$ coleta.
\end{abstract}

Palavras chave: colunas de solo, biossólido, lodo

\section{Leaching of ions after the application of organic residues of a pharmochemical industry}

\begin{abstract}
In the last decades, increasing amounts of industrial residues have been deposited in the soil in either a planned way, or accidentally. The objective of this work is to evaluate the impact of the application of a high dose of organic residues (Biossolid - Bs and Sludge - Sd) produced by a pharmochemical industry on the contamination of spring waters. Therefore, an experiment was set up in PVC columns of $20 \times 120 \mathrm{~cm}$ (diameter $\times$ height) in a factorial design $2 \times 2 \times 2+2$ with, 2 soils ( $N V d f$ and PVd), 2 residues (Bs and Sd), 2 forms of application of 1 million $\mathrm{L} \mathrm{ha}^{-1}$ (incorporated and on surface), and a control for each soil. In each column, ten water applications were performed corresponding to $120 \%$ of the water column holding capacity; the leached water was collected to evaluate its chemical attributes. EC of the leached water presented a decrease from 1 st to the 2 nd water application, and the $\mathrm{pH}$ increased until the fourth water application. The appraised ions presented different behaviors; those that form outer sphere complex $\left(\mathrm{NO}_{3}{ }^{-}, \mathrm{Cl}^{-}, \mathrm{Ca}^{2+}, \mathrm{Mg}^{2+}\right.$ and $\left.\mathrm{Na}^{+}\right)$ had fast leaching. The nutrients that form inner sphere complex behaved differently, and $\mathrm{PO}_{4}{ }^{3-}$ presented low leaching, while $\mathrm{K}^{+}$leached less than the control and $\mathrm{SO}_{4}{ }^{2-}$ leached more after the $3 \mathrm{rd}$ water application.
\end{abstract}

Key words: soil columns, biosolid, sludge 


\section{INTRODUÇÃO}

Não apenas no Brasil mas também em outros países, grandes quantidades de resíduos têm sido depositadas sobre o solo de forma planejada, como fonte de nutrientes para as plantas (Silva et al., 2004; Nascimento et al., 2004), na destinação final de resíduos em lixões (Sisinno \& Moreira, 1996; Sisinno, 2003), ou de forma acidental, através do rompimento de barragens, infiltração de esgotos provenientes de lagoas de tratamento de águas reiduárias ou armazenagem de resíduos (Silva et al., 2002).

Um dos materiais orgânicos mais estudados é o biossólido das unidades de tratamento de esgoto urbano, cujo uso na agricultura é uma forma benéfica de reciclar os resíduos tratados das estações de tratamento de esgotos. Este resíduo, além de conter nutrientes e matéria orgânica, melhora as características químicas, físicas e biológicas do solo, tendo potencial, ainda, para melhorar a produtividade das culturas (Cooke et al., 2001), no entanto, as perdas em profundidade dos nutrientes (Costa et al., 1999) liberados pelos resíduos, podem contaminar os mananciais subterrâneos ou serem carregados em superfície para rios e lagos, degradando a qualidade dos ecossistemas aquáticos.

Entre os nutrientes presentes nos resíduos sólidos, $\mathrm{NO}^{3-}$ e $\mathrm{PO}_{4}{ }^{2-}$ podem promover a eutrofização de rios e lagos por favorecerem a proliferação de algas capazes de produzir toxinas e diminuir o conteúdo de oxigênio nas camadas subsuperficiais da água; ambos os problemas atuam negativamente nos organismos aquáticos (Shuman, 2002).

$\mathrm{O} \mathrm{NO}_{3}^{-}$é o ânion mais estudado na literatura com relação à sua lixiviação no perfil do solo (Mortensen et al., 1998; Costa et al., 1999; Hansen et al., 2000; Assadi et al., 2002; Basso et al., 2005); contudo, um grande número de trabalhos publicados recentemente mostram que as perdas de fósforo em solos por lixiviação tem recebido maior atenção em relação à contaminação dos mananciais por este elemento (Cooke et al, 2001; Shuman, 2002; Basso et al., 2005).

Estudos de percolação de $\mathrm{Ca}^{2+}$ e $\mathrm{Mg}^{2+}$ são pouco realizados, sendo a maior quantidade realizada com o intuito de se verificar a existência da movimentação desses elementos no perfil do solo, sobretudo para camadas subsuperficiais, devido à gessagem (Pavan, 1981; Ernani et al., 2001) ou em virtude da aplicação por calagem (Pavan, 1981; Amaral et al., 2004).

$\mathrm{O} \mathrm{SO}_{4}{ }^{2-}$, o $\mathrm{Ca}^{2+}$ e o $\mathrm{Mg}^{2+}$, são espécies iônicas que contribuem para a concentração total de sólidos dissolvidos na água percolada (Jang \& Townsend, 2001); mesmo assim, poucos trabalhos têm sido direcionados à preocupação com a lixiviação de sulfato e a contaminação das águas, avaliando-se basicamente, como parte da composição química do material aplicado (Pavan, 1981; Jang \& Tawnsend, 2001).

Os íons em solução interagem com a fase sólida do solo, formando diferentes complexos que afetam sua adsorção e/ ou mobilidade. Íons altamente hidratados $\left(\mathrm{Ca}^{2+}, \mathrm{Mg}^{2+}, \mathrm{Na}^{+}\right.$, $\mathrm{Cl}^{-}, \mathrm{NO}_{3}{ }^{-}$) compõem complexos de esfera externa com a fase sólida do solo (Sposito, 1989), movimentando-se mais livremente com a passagem da água; entretanto, outros íons como o $\mathrm{PO}_{4}{ }^{3-}$ e o $\mathrm{K}^{+}$, formam complexos de esfera interna com os componentes minerais dos solos (Sposito, 1989); desta for- ma, o íon $\mathrm{PO}_{4}{ }^{3-}$ apresenta baixa mobilidade, considerada insignificante por alguns autores (Basso et al., 2005).

Outro fator importante, que influencia a dinâmica dos íons em solução, está relacionado à textura do solo, pois a retenção física, em função do tamanho de partícula, exerce forte influência sobre a capacidade suporte do solo (Iwai, 2005); desta forma, agregados de menor tamanho promovem maior retenção de amônio (Coelho et al., 2000).

A estrutura dos solos também poderia ser um fator de influência na dinâmica dos nutrientes no solo; contudo, existem trabalhos que mostram que não têm ocorrido diferenças entre solo com estrutura natural daqueles com estrutura deformada (Benito et al., 2001; Ludwig \& Kölbl, 2002).

Diante do exposto, com vistas a se avaliar o potencial poluente de altas doses de dois resíduos industriais orgânicos, montou-se um ensaio em colunas de solo com estrutura deformada, para avaliar a dinâmica de íons em dois solos (Nitossolo Vermelho distroférrico e Argissolo Vermelho distófico) representativos do estado do Paraná.

\section{MATERIAL E MÉTODOS}

O ensaio de lixiviação foi montado em casa de vegetação, consistindo de tubos de PVC de 20 x $120 \mathrm{~cm}$, com a extremidade basal fechada por uma tampa, perfurada e acoplada a uma saída, para permitir recolhimento da solução percolada.

Utilizaram-se, para o preenchimento das colunas 2 solos, sendo um Argissolo Vermelho distrófico de textura média (PVd) e um Nitossolo Vermelho distroférrico de textura argilosa (NVdf); esses solos foram amostrados a campo nas seguintes camadas: 0-20; 20-40; 40-70 e 70-100 cm de profundidade; de cada camada foram retirados $250 \mathrm{~kg}$ que foram posteriormente secas ao ar e peneiradas (peneira com abertura de $2 \mathrm{~mm}$ ); sub-amostras de cada camada foram submetidas a caracterização química e física, segundo as metodologias descritas pela EMBRAPA (1997), cujos resultados analíticos se encontram nas Tabelas 1 e 2.

As colunas foram montadas com altura de $100 \mathrm{~cm}$ respeitando-se a seqüência das camadas coletadas e sua densidade.

O experimento foi montado em 10 colunas, foram aplicados 2 resíduos em dois solos (NVdf e PVd), sob duas formas de aplicação, além de uma testemunha para cada solo.

Os dois resíduos utilizados são oriundos de uma indústria farmoquímica, denominados: lodo (Lo) e biossólido (Bs). A diferença básica entre os dois resíduos é que o Lo é resultado da flotação de todos os efluentes orgânicos com sulfato de alumínio, enquanto o Bs é o produto da decomposição biológica aeróbica dos resíduos orgânicos industriais em lagoas de tratamento. Os resíduos foram aplicados em dosagem única correspondente a 1 milhão de litros por hectare, quantidade aproximada dos resíduos produzidos pela indústria durante um ano; esta aplicação foi realizada de 2 formas: em uma, os resíduos foram aplicados diretamente na superfície das colunas e, na outra, os resíduos foram aplicados e incorporados mecanicamente com uma espátula, a uma quantidade de solo correspondente à camada superficial, que seria depositada nas colunas $(0-5 \mathrm{~cm})$ permitindo reagir por 60 dias. 
Tabela 1. Caracterização química dos solos utilizados para preencher as colunas (média de duplicatas)

\begin{tabular}{|c|c|c|c|c|c|c|c|c|c|c|c|}
\hline \multirow{2}{*}{$\begin{array}{l}\text { Profundidade } \\
\text { (cm) }\end{array}$} & \multirow{2}{*}{$\begin{array}{c}\mathrm{pH} \\
\mathrm{CaCl}_{2}\end{array}$} & \multirow{2}{*}{$-\Delta \mathrm{pH}$} & $\mathrm{Al}^{+++}$ & $\mathrm{H}+\mathrm{Al}$ & $\mathrm{Ca}$ & $\mathrm{Mg}$ & $\mathrm{K}^{+}$ & SB & CTC & \multirow{2}{*}{$\begin{array}{c}P \\
\mathrm{mg} \mathrm{dm}^{-3}\end{array}$} & \multirow{2}{*}{$\begin{array}{c}C \\
\mathrm{~g} \mathrm{dm^{-3 }}\end{array}$} \\
\hline & & & \multicolumn{7}{|c|}{$\mathrm{cmol}_{\mathrm{c}} \mathrm{dm}^{-3}$} & & \\
\hline & \multicolumn{11}{|c|}{ Nitossolo Vermelho distroférrico (NVdf) } \\
\hline $0-20$ & 5,3 & 0,64 & 0,0 & 2,5 & 3,7 & 1,6 & 0,6 & 5,9 & 8,4 & 3,1 & 12,8 \\
\hline $20-40$ & 5,4 & 0,43 & 0,0 & 2,2 & 4,4 & 1,4 & 0,2 & 6,0 & 8,1 & 1,6 & 9,3 \\
\hline $40-70$ & 5,7 & 0,34 & 0,0 & 1,8 & 4,8 & 1,2 & 0,1 & 6,1 & 7,9 & 2,1 & 5,7 \\
\hline \multirow[t]{2}{*}{$70-100$} & 5,9 & 0,47 & 0,0 & 1,7 & 4,6 & 1,6 & 0,0 & 6,2 & 8,0 & 3,4 & 4,9 \\
\hline & \multicolumn{11}{|c|}{ Argissolo Vermelho distrófico (PVd) } \\
\hline $0-20$ & 6,2 & 0,95 & 0,0 & 1,2 & 2,4 & 1,4 & 0,1 & 4,0 & 5,1 & 2,8 & 4,5 \\
\hline $20-40$ & 6,2 & 0,98 & 0,0 & 1,2 & 2,9 & 1,5 & 0,0 & 4,4 & 5,7 & 1,5 & 3,2 \\
\hline $40-70$ & 5,0 & 0,68 & 0,1 & 1,7 & 3,0 & 0,9 & 0,0 & 3,9 & 5,6 & 1,2 & 3,2 \\
\hline $70-100$ & 4,4 & 0,75 & 1,1 & 1,9 & 1,6 & 0,7 & 0,0 & 2,3 & 4,2 & 1,4 & 2,4 \\
\hline
\end{tabular}

Determinações realizadas segundo metodologia da EMBRAPA (1997), $-\Delta \mathrm{pH}=\mathrm{pH}$ em KCl $1 \mathrm{M}-\mathrm{pH}$ em H $\mathrm{H}_{2} \mathrm{O}$; $\mathrm{SB}=$ Soma de Bases; CTC = capacidade de troca catiônica

Tabela 2. Análise granulométrica da TFSA (média de duplicata) e mineralógica da fração argila das camadas de solo coletadas a campo, para preencher as colunas

\begin{tabular}{|c|c|c|c|c|c|}
\hline \multirow{3}{*}{ Amostra } & \multicolumn{4}{|c|}{ Análise Granulométrica } & \multirow{3}{*}{ Mineralogia da fração argila(2) } \\
\hline & A.G.(1) & A.F.(1) & Silte(1) & Argila(1) & \\
\hline & \multicolumn{4}{|c|}{$\mathrm{g} \mathrm{Kg}^{-1}$} & \\
\hline \multicolumn{6}{|c|}{ Nitossolo Vermelho distroférrico (NVdf) } \\
\hline $0-20$ & 150 & 192 & 60 & 598 & Cau. $>>>$ 0.F. $>>$ Verm. $>$ Gib. \\
\hline $20-40$ & 140 & 175 & 40 & 645 & Cau. $>>>$ 0.F. $>>$ Verm. $>$ Gib. \\
\hline $40-70$ & 110 & 170 & 60 & 660 & Cau. $>>>$ 0.F. $>>$ Verm. $>$ Gib. \\
\hline $70-100$ & 110 & 160 & 60 & 670 & Cau. $>>>$ 0.F. $>>$ Verm. $>$ Gib. \\
\hline \multicolumn{6}{|c|}{ Argissolo Vermelho distrófico (PVd) } \\
\hline $0-20$ & 360 & 440 & 10 & 190 & Cau. $>>>$ 0.F. $>>$ Gib. $>$ Verm. \\
\hline $20-40$ & 320 & 430 & 10 & 240 & Cau. $>>>$ 0.F. $>>$ Gib. $>$ Verm. \\
\hline $40-70$ & 310 & 340 & 20 & 330 & Cau. $>>>$ 0.F. $>>$ Gib. $>$ Verm. \\
\hline $70-100$ & 290 & 320 & 20 & 370 & Cau. $>>>$ 0.F. $>>$ Gib. $>$ Verm. \\
\hline
\end{tabular}

A.G.: Areia grossa; A.F.: Areia fina; Cau.: Caulinita; 0.F.: Óxidos de ferro; Verm.: Vermiculita; Gib.: Gibbsita

(1) Método da Pipeta; (2) DRX - difração de raios X da fração argila

Determinou-se o teor de umidade dos resíduos pela diferença de massa após a secagem das amostras a $65^{\circ} \mathrm{C}$, em estufa com circulação forçada de ar, até atingirem peso constante.

A determinação dos íons presentes nos resíduos foi realizada após duas digestões no material seco, nitro-perclórica e sulfúrica, de um volume conhecido dos materiais.

No extrato da digestão nitro-perclórica realizou-se a determinação dos teores totais de $\mathrm{Al}^{3+}, \mathrm{Ca}^{2+}, \mathrm{Mg}^{2+}, \mathrm{K}^{+}, \mathrm{Na}^{+}$, $\mathrm{SO}_{4}{ }^{2-}, \mathrm{PO}_{4}{ }^{3-}, \mathrm{Al}^{3+}, \mathrm{Ca}^{2+}$ e $\mathrm{Mg}^{2+}$ foram determinados em espectrometria de absorção atômica (CG analítica modelo 932), em chama de ar acetileno, com a adição de $\mathrm{KCl}$ para a leitura do $\mathrm{Al}^{3+}$ e lantânio para a leitura de $\mathrm{Ca}^{2+}$ e $\mathrm{Mg}^{2+}$ (EMBRAPA, 1997).

Realizou-se a determinação de $\mathrm{K}^{+}$e $\mathrm{Na}^{+}$por fotometria de chama (fotômetro Micronal modelo B462), efetuando-se a leitura diretamente do extrato (EMBRAPA, 1997). $\mathrm{SO}_{4}{ }^{2-} \mathrm{e}$ $\mathrm{PO}_{4}{ }^{3-}$ foram determinados por espectrofotometria (espectrofotômetro da Micronal modelo B295II), sendo o $\mathrm{SO}_{4}{ }^{2-}$ de- terminado por turbidimetria e o $\mathrm{PO}_{4}{ }^{3-}$ por colorimetria com metavanadato (Malavolta et al., 1997). O nitrogênio total foi determinado pelo método Kjeldahl, após digestão utilizando-se mistura de ácido sulfúrico, sulfato de sódio e selênio (Malavolta, et al.,1997)

$\mathrm{O} \mathrm{Cl}^{-}$foi determinado por complexometria, titulando o extrato, obtido através de digestão sulfúrica dos materiais, com $\mathrm{AgNO}_{3}$ na presença de $\mathrm{KCrO}_{4}$ como indicador (Malavolta et al., 1997).

$\mathrm{O} \mathrm{pH}$ foi determinado no extrato bruto dos resíduos depois de serem agitados durante 10 minutos e filtrados. Os teores de matéria orgânica foram determinados pela diferença de massa da amostra após incineração em mufla a $550{ }^{\circ} \mathrm{C}$.

Os teores dos elementos encontrados nos resíduos são apresentados na Tabela 3 , média de 3 repetições.

$\mathrm{O}$ volume de poros de cada coluna foi determinado adicionando-se lentamente volumes conhecidos de água até a saturação, sendo as colunas cobertas com papel alumínio

Tabela 3. Características químicas dos resíduos utilizados

\begin{tabular}{|c|c|c|c|c|c|c|c|c|c|c|c|}
\hline \multirow{2}{*}{ Resíduo } & $\mathrm{pH}$ & MO & NT & $\mathrm{Al}^{3+}$ & $\mathrm{Ca}^{2+}$ & $\mathrm{Mg}^{2+}$ & $\mathrm{K}^{+}$ & $\mathrm{Na}^{+}$ & $\mathrm{Cl}^{-}$ & $\mathrm{SO}_{4}{ }^{2-}$ & $\mathrm{PO}_{4}{ }^{3-}$ \\
\hline & $\mathrm{H}_{2} \mathrm{O}$ & \multicolumn{10}{|c|}{$\mathrm{g} \mathrm{L}^{-1}$} \\
\hline Lodo & 5,8 & 35,44 & 1,19 & 0,0012 & 0,46 & 0,04 & 1,96 & 1,05 & 19,2 & 0,42 & 0,57 \\
\hline Biossólido & 8,00 & 24,47 & 1,62 & 0,0132 & 0,87 & 0,17 & 2,42 & 5,19 & 7,9 & 0,11 & 1,11 \\
\hline
\end{tabular}

MO: Matéria orgânica; NT: Nitrogênio total 
permitindo-se a drenagem da água retida nos macroporos pela base da coluna por $24 \mathrm{~h}$. A quantidade de água retida na coluna foi determinada subtraindo-se o volume drenado do aplicado, resultando em valores médios de 6,0 e 6,5 L para os solos PVd e NVdf, respectivamente. Para cada solo foram adicionados $20 \%$ do volume de água além da retida, para favorecer o processo de lixiviação e descontar eventuais perdas de água por evaporação da superfície da coluna, após a aplicação dos pulsos de água.

A água percolada de cada um dos volumes aplicados foi recolhida em frascos de polietileno de $10 \mathrm{~L}$, tampados, visando evitar a contaminação do lixiviado; realizaram-se, no total, 10 pulsos de água, em intervalos de 7 dias.

Imediatamente após a coleta do lixiviado em cada pulso de água, foram determinados a condutividade elétrica (CE), o pH e o oxigênio dissolvido (OD), utilizando-se aparelhos da marca Hanna instruments modelos HI 9142 (OD), HI 8033 (CE) e HI 9321 (pH).

Após as primeiras avaliações uma parte das amostras foi separada e congelada para posterior determinação de $\mathrm{NO}_{3}{ }^{-}$e $\mathrm{Cl}^{-}$e outra parte foi acidificada utilizando-se $5 \mathrm{~mL}$ de ácido clorídrico concentrado em $500 \mathrm{~mL}$ da amostra, na qual se realizaram as determinações de $\mathrm{SO}_{4}{ }^{2-}, \mathrm{NH}_{4}{ }^{+}, \mathrm{PO}_{4}{ }^{3-}, \mathrm{Ca}^{2+}$, $\mathrm{Mg}^{2+}, \mathrm{K}^{+}$e $\mathrm{Na}^{+}$.

As determinações dos teores de $\mathrm{NH}_{4}{ }^{+}, \mathrm{PO}_{4}{ }^{3-}, \mathrm{NO}_{3}{ }^{-}, \mathrm{Ca}^{2+}$, $\mathrm{Mg}^{2+}, \mathrm{K}^{+}$e $\mathrm{Na}^{+}$na solução percolada foram realizadas conforme EMBRAPA (1997), sendo que $\mathrm{Ca}^{2+}$ e $\mathrm{Mg}^{2+}$ foram analisados em espectrometria de absorção atômica, $\mathrm{K}^{+}$e $\mathrm{Na}^{+}$em fotometria de emissão de chama e $\mathrm{PO}_{4}{ }^{2-}$ avaliado por colorimetria. Os teores de $\mathrm{SO}_{4}{ }^{2-}$ foram obtidos por turbidimetria e os de $\mathrm{Cl}^{-}$por titulometria, conforme metodologias descritas por Malavolta et al. (1997).

A análise estatística dos resultados constou de análise de variância, correlações de Pearson e testes de média (Tukey) utilizando-se o programa estatístico SAS (SAS, 2001)

\section{RESULTADOS E DISCUSSÃO}

\section{Atributos químicos da água percolada}

As avaliações iniciais mostraram que os valores de $\mathrm{pH}$ do percolado tendiam à elevação independente do tratamento aplicado. A variação nos valores de $\mathrm{pH}$ apresentou-se maior no PVd (Figura 1B), no qual se observaram valores entre 5,1 e 6,2, enquanto no NVdf, entre 5,6 e 6,4 (Figuras 1A e B).

A maior variação no $\mathrm{pH}$ do $\mathrm{PVd}$ era prevista em virtude do seu menor poder tampão, pois sua CTC $\left(5,09 \mathrm{cmol}_{\mathrm{C}} \mathrm{dm}^{-3}\right)$ é menor que a do NVdf $\left(8,06 \mathrm{cmol}_{\mathrm{C}} \mathrm{dm}^{-3}\right)$.

Os valores de $\mathrm{pH}$ do NVdf mostraram aumento até a $6^{\mathrm{a}}$ coleta, na quase totalidade dos tratamentos, sendo que esses últimos valores corresponderam aos maiores valores de $\mathrm{pH}$ observado, média de 6,09 contra 5,69 obtidos nos tratamentos do primeiro pulso (Figura 1A); após o $6^{\circ}$ pulso, os valores de $\mathrm{pH}$ variaram; contudo, nunca foram menores que os valores encontrados na primeira coleta. No caso do NVdf, o valor médio de 6,09 , além de ser o ponto que marca o término do crescimento contínuo dos valores, e foi também o maior valor médio obtido.
Comparando-se os solos, observa-se que os valores de $\mathrm{pH}$ no PVd aumentaram continuamente até o terceiro pulso de água obtendo-se, neste ponto, valores médios de 5,81 contra 5,33 unidades de $\mathrm{pH}$ da primeira coleta de água (Figura 1B); após o $3^{\circ}$ pulso de água, os valores de $\mathrm{pH}$ oscilam, ora para menos, ora para mais que os obtidos na terceira coleta; no entanto, nunca inferiores ao valor médio de $\mathrm{pH}$ obtido no $1^{\circ}$ pulso de água. Neste solo, os maiores valores de $\mathrm{pH}$ foram, na maioria dos tratamentos, obtidos no $7^{\circ}$ pulso de água, apresentando o valor médio de pH de 5,96.

Na média geral, os tratamentos com Bs apresentaram valores de $\mathrm{pH}$ maiores que os tratamentos que receberam Lo, com valores médios de 5,91 e 5,80, respectivamente, diferentes estatisticamente a nível de $5 \%$. O maior valor de $\mathrm{pH}$ com a aplicação de Bs é decorrente do valor de $\mathrm{pH}$ inicial apresentado pelo resíduo (Tabela 3).

Os valores de $\mathrm{pH}$ de soluções percoladas em experimentos de colunas são bem variados obtendo-se reduções dos valores de $\mathrm{pH}$, mesmo em experimentos que receberam a aplicação de calcário (Amaral et al., 2004) ou pequenos aumentos somente nos valores iniciais (Pavan, 1981).

Devido à liberação de ácidos orgânicos pela matéria orgânica durante sua decomposição, esperava-se diminuição dos valores de $\mathrm{pH}$, sobretudo no resíduo Lo que não possui um pH básico e tem grande quantidade de carbono orgânico (Brady, 1989; Cheung \& Venkitachalam, 2004); desta forma, a elevação dos valores de $\mathrm{pH}$ deve estar associada à alcalinidade dos resíduos aplicados, promovendo a incorporação de grandes quantidades de $\mathrm{Ca}^{2+}, \mathrm{Mg}^{2+}, \mathrm{K}^{+}$e $\mathrm{Na}^{+}$ ao solo (Tabela 3 ).

Os tratamentos testemunhas também tiveram crescimento nos valores de $\mathrm{pH}$ semelhante aos demais tratamentos nos solos utilizados, mostrando que este comportamento não foi somente devido à adição dos resíduos.

Quando se avalia apenas o solo, descartando-se os tratamentos com os resíduos, observa-se que o solo NVdf apresentou maiores valores médios de $\mathrm{pH}(5,93)$, média estatisticamente superior ao valor de $\mathrm{pH}$ do $\mathrm{PVd}$, que foi de 5,74 $(\mathrm{p}<0,05)$.

Visualmente, os valores de OD apresentam uma variação muito maior que a do pH (Figuras 1A, B, C e D), sendo valores aparentemente indiferentes aos tratamentos utilizados.

Quando se avalia o oxigênio dissolvido sem se considerar os resíduos, pode-se observar que o PVd possui maiores valores de OD, média de 5,55 contra 5,21 mg L $\mathrm{m}^{-1}$ do NVdf; observa-se então que o solo que mostra menor valor de OD tem maior valor de $\mathrm{pH}$, isto se deve ao fato de que ambientes oxidantes apresentam condições químicas favoráveis ao acúmulo de prótons (Sposito, 1989), o que promove o decréscimo nos valores de $\mathrm{pH}$.

O aumento no teor de matéria orgânica e bases do solo, devido à aplicação dos resíduos, em conjunto com a aplicação semanal de água e à descontinuidade do solo na base da coluna, devem ter favorecido condições de umidade elevada que, embora não tenham mostrado sinais de processos de redução dos minerais presentes nos solos, podem ter favorecido condições redutoras dentro dos agregados tamisados, promovendo pequenas elevações do $\mathrm{pH}$ da solução (Sposito, 
A.

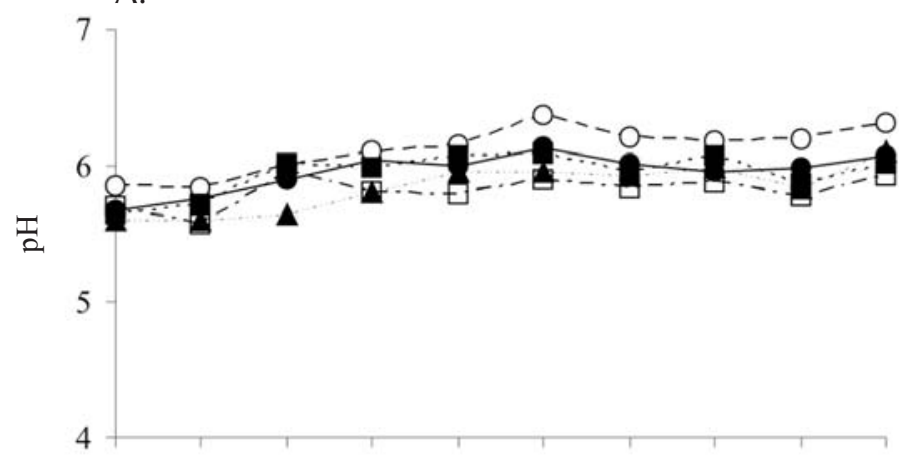

B.

7

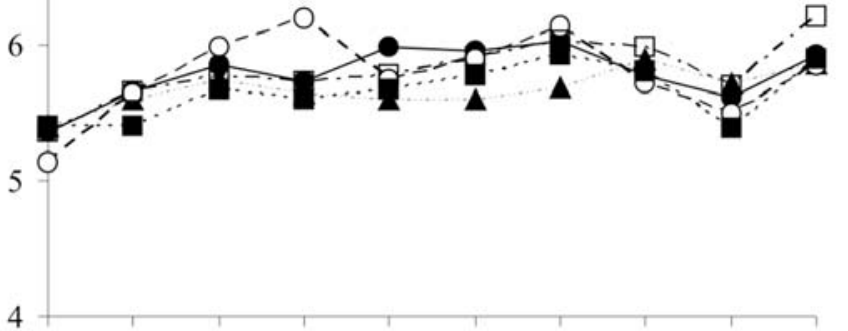

D.
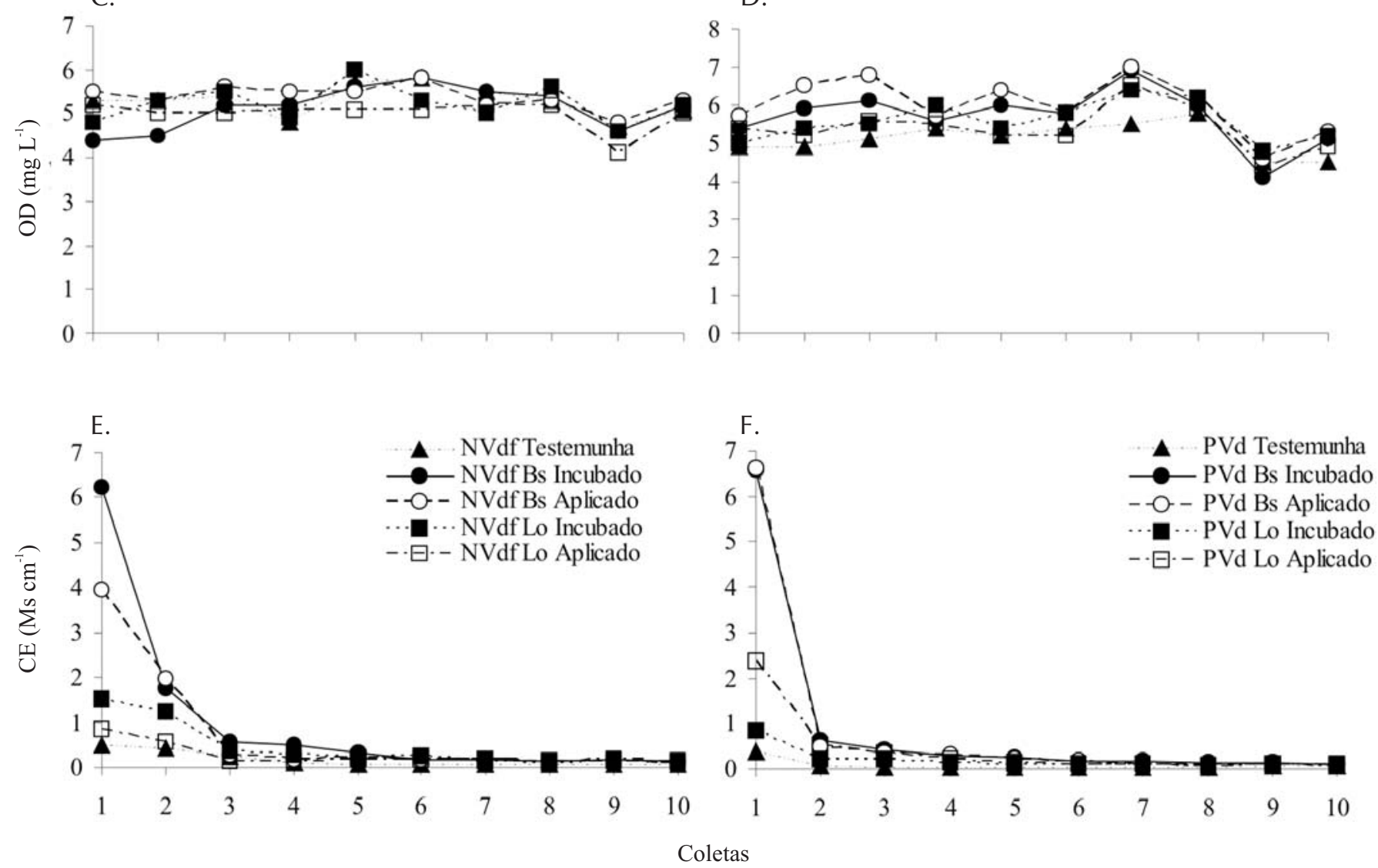

Figura 1. Valores de $\mathrm{pH}$, oxigênio dissolvido (OD) e condutividade elétrica (CE), analisados na água percolada das colunas tratadas com 2 resíduos, Biossólido (Bs) e Lodo (Lo), nos dois solos utilizados, Nitossolo Vermelho distroférrico (NVdf) e Argissolo Vermelho distrófico (PVd)

1989); referidas elevações são maiores nos solos que apresentam maior microporosidade, ou seja, solos com maior teor de argila (NVdf), apresentam maior retenção de água, ensejando menores valores de OD e maiores valores de $\mathrm{pH}$.

Os maiores valores de condutividade elétrica (CE) da solução percolada ocorreram nos tratamentos que receberam o resíduo Bs (Figuras 1E e F) o qual apresentou valor médio para os dois solos nos 10 pulsos de água, de $0,8735 \mathrm{mS} \mathrm{cm}^{-1}$ sendo estatisticamente superior pelo teste de Tukey (a nível de $5 \%$ ) aos $0,3278 \mathrm{mS} \mathrm{cm}^{-1}$ apresentados pela Lo, nas mesma condições.

Não ocorreu diferença estatística entre os solos para os valores de CE visto que a média geral foi de 0,614 e $0,5873 \mathrm{mS} \mathrm{cm}^{-1}$, respectiva aos solos NVdf e PVd.
Como a CE é um indicador da quantidade de íons (cátions e ânions) em solução, uma quantidade maior destes, propicia também maior CE (Amaral et al., 2004); pode-se concluir, então, que a maior parte dos íons fornecidos pelos resíduos lixiviou rapidamente (Figuras $1 \mathrm{E}$ e F), sendo que no terceiro pulso os valores de CE correspondiam a 9,2\% do valor obtido no primeiro (cálculo efetuado nos valores médios de todas as colunas que receberam um resíduo orgânico); a redução dos valores de CE também foi observada por outros autores utilizando compostos minerais (Amaral et al., 2004) ou orgânicos (Agassi et al., 1998).

\section{Cátions lixiviados}

Para se avaliar os cátions lixiviados pelos diferentes 
tratamentos, plotaram-se gráficos com as massas acumuladas de cada cátion, em função do solo, resíduo e forma de aplicação, subtraídos das massas dos cátions obtidas nos tratamentos testemunhas (Figura 2); desta forma, quando se avalia a massa dos cátions lixiviados das colunas, vê-se que na média geral dos tratamentos cerca de $92 \%$ de todo o $\mathrm{Ca}^{2+}$ e $\mathrm{Mg}^{2+}$ são lixiviados até o $3^{\circ}$ pulso de água (Figuras 2A, B, C e D); este comportamento do $\mathrm{Ca}^{2+}$ e do $\mathrm{Mg}^{2+}$ é semelhante ao da CE (Figuras $1 \mathrm{E}$ e F), comprovado pela correlação de Pearson $(r=0,93, p<0,01)$ entre a soma das cargas promovidas pelo $\mathrm{Ca}^{2+}$ e $\mathrm{Mg}^{2+}$ com CE.

Ainda acompanhando a CE, nota-se que o resíduo Bs promoveu a lixiviação das maiores massas, de $\mathrm{Ca}^{2+}$ e de $\mathrm{Mg}^{2+}$, mesmo tendo este resíduo menor teor de íons que o resíduo Lo (Tabela 3), obtendo-se médias diferentes estatisticamente $(\mathrm{p}<0,05)$, de 0,59 e $0,19 \mathrm{~g}$ para o $\mathrm{Ca}^{2+}$ e 0,10 e 0,030 g para o $\mathrm{Mg}^{2+}$ lixiviados para os tratamentos Bs e Lo, respectivamente. Quando se compara o valor de $\mathrm{Ca}^{2+}$ e $\mathrm{Mg}^{2+}$ entre os solos, não se observa diferença estatística ( $p>0,05)$.

A rápida lixiviação de $\mathrm{Ca}^{2+}$ e $\mathrm{Mg}^{2+}$ pelos solos não é observada em todos os trabalhos (Pavan, 1981), visto que são íons que apresentam certa afinidade pelos colóides em função das suas cargas e raio iônico, sendo retidos em preferência a outros elementos, como o $\mathrm{K}^{+}$e o $\mathrm{Na}^{+}$(Sposito, 1989); contudo, o $\mathrm{Ca}^{2+}$ e o $\mathrm{Mg}^{2+}$ formam complexos de esfera externa com os colóides do solo, fenômenos de superfície cujos íons solvatados se ligam com as cargas existentes nos colóides (Sposito, 1989); desta forma, os referidos cátions estão no complexo de troca fracamente adsorvidos, podendo ser deslocados por outros cátions e, assim, ser lixiviados.

Os elevados teores de alumínio trocável existente nos resíduos (Tabela 3), sobretudo no Lo, favorecem a lixiviação de $\mathrm{Ca}^{2+}$ e $\mathrm{Mg}^{2+}$ por serem preferencialmente adsorvidos às cargas superficiais dos colóides do solo e deslocar esses cátions hidratados de menor valência para a solução. A maior lixiviação de $\mathrm{Ca}^{2+}$ e $\mathrm{Mg}^{2+}$, no NVdf, no tratamento biossólido aplicado se deve à incompleta humificação do resíduo que não favoreceu a retenção dos cátions.

A estrutura granular dos solos argilosos apresenta maiores valores de condutividade hidráulica que os solos de textura média, fato que pode ser observado quando se adiciona água às colunas e o PVd necessitava de maior tempo para o completo escoamento da água aplicada.

A maior lixiviação de $\mathrm{Ca}^{2+}$ apresentada no $\mathrm{NVdf}$ pode estar relacionada à maior condutividade hidráulica deste solo que, após ter o complexo de troca saturado com os cátions provenientes dos resíduos, favoreceu a sua lixiviação.

$\mathrm{O} \mathrm{Na}{ }^{+}$apresentou comportamento inicial semelhante ao do $\mathrm{Ca}^{2+}$ e $\mathrm{Mg}^{2+}$, isto é, intensa lixiviação no início, mas, diferentemente desses cátions após o segundo pulso de água, apresentou contínua lixiviação com as aplicações subseqüentes (Figuras 2E e F).

A contínua perda apresentada pelo $\mathrm{Na}^{+}$mostra que ele ocupou parte das cargas do complexo de troca do solo e daquelas criadas pela decomposição dos resíduos orgânicos, mesmo não sendo adsorvido preferencialmente, uma vez que apresenta grande raio iônico e é monovalente. A preferência pela adsorção do $\mathrm{Na}^{+}$é devida à maior concentração deste elemento nos resíduos, com teores 2,1 e 5 vezes maiores que o $\mathrm{Ca}^{2+}+\mathrm{Mg}^{2+}$, para os resíduos Lo e Bs (Tabela 3), respectivamente.

Os teores finais de $\mathrm{Na}^{+}$lixiviado em ambos os solos, foram semelhantes embora as médias para os solos não tenham apresentado diferença estatística ( $>$ > 0,05), 0,26 e 0,32 g do NVdf e PVd, respectivamente, mas o NVdf mostrou maior capacidade de reter o elemento já que, no primeiro pulso de água, indicou valores de massa do elemento lixiviado bem menores que o PVd. A maior adsorção de $\mathrm{Na}^{+}$pode ter ajudado a deslocar o $\mathrm{Ca}^{2+}$ e o $\mathrm{Mg}^{2+}$ dos complexos de troca daquele solo, facilitando a sua lixiviação (Figuras 2A, C e E).

$\mathrm{O} \mathrm{K}^{+}$, cujo comportamento foi diferenciado entre os cátions avaliados, teve seus valores da massa acumulada de $\mathrm{K}^{+}$ lixiviado menores que os apresentados pela testemunha (Figuras 2G e H), menos para o tratamento com Lo incubada no solo PVd, significando que ocorreu baixa lixiviação deste cátion já que os valores médios em gramas do lixiviado separados nos resíduos foram de 0,73 gA, 0,66 gA e 0,52 gB (teste de Tukey, $\mathrm{p}<0,05$ ) nos tratamentos testemunha, Lo e Bs, respectivamente.

Os menores teores de $\mathrm{K}^{+}$obtidos nos lixiviados em relação ao tratamento testemunha indicam que os resíduos, mesmo se adicionando $\mathrm{K}^{+}$aos solos (Tabela 3 ), aumentaram a retenção deste cátion; a retenção do $\mathrm{K}^{+}$ocorre em virtude da formação de complexos de esfera interna com minerais de argila do tipo 2:1, devido ao raio iônico do $\mathrm{K}^{+}$favorecer sua retenção nas cavidades ditrigonais existentes nesse tipo de mineral de argila (Sposito, 1989) (Tabela 3). Souza Júnior (2001), trabalhando com a fração argila de diversas classes de solo da região sul do Brasil, encontrou valores médios de $42 \%$ de capacidade de fixação de $\mathrm{K}^{+}$.

Embora os minerais do tipo 2:1 existam em pequenas quantidades nos solos avaliados, a elevada umidade associada à adição maciça de cátions pode ter promovido aumento no grau de dispersão das partículas da fração argila, aumentando o contato dos íons $\mathrm{K}^{+}$em solução com as argilas do tipo 2:1 favorecendo, desta forma, maior retenção do íon.

$\mathrm{O}$ único tratamento em que o $\mathrm{K}^{+}$apresentou uma lixiviação maior que o tratamento testemunha, foi com o Lo incubado no solo PVd (Figura 2H); este tratamento apresentou as menores quantidades lixiviadas dos demais cátions avaliados (Figuras 2B, D e F).

\section{Ânions lixiviados}

Neste ensaio, devido à grande imobilização inicial do nitrogênio pela atividade biológica, o $\mathrm{NO}_{3}{ }^{-}$apresentou baixa lixiviação no primeiro pulso de água; os segundo e terceiro pulsos de água mostraram valores maiores do ânion no lixiviado (Figuras 3A e B), e o $\mathrm{NO}_{3}{ }^{-}$indicou valores superiores a $90 \%$ do total lixiviado nos $8^{\circ}$ e $9^{\circ}$ pulsos de água, nos solos NVdf e PVd, respectivamente. A lixiviação mais lenta, inicialmente apresentada pelo $\mathrm{NO}_{3}{ }^{-}$, também foi verificada por outros autores, como Sutton (1982), Warman (1986), e Basso et al. (2005).

O resíduo Lo, aplicado superficialmente no NVdf, deve 


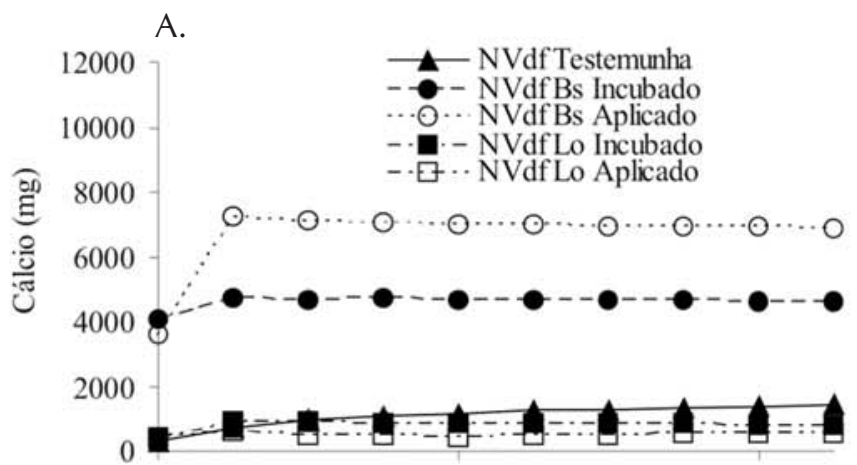

C.

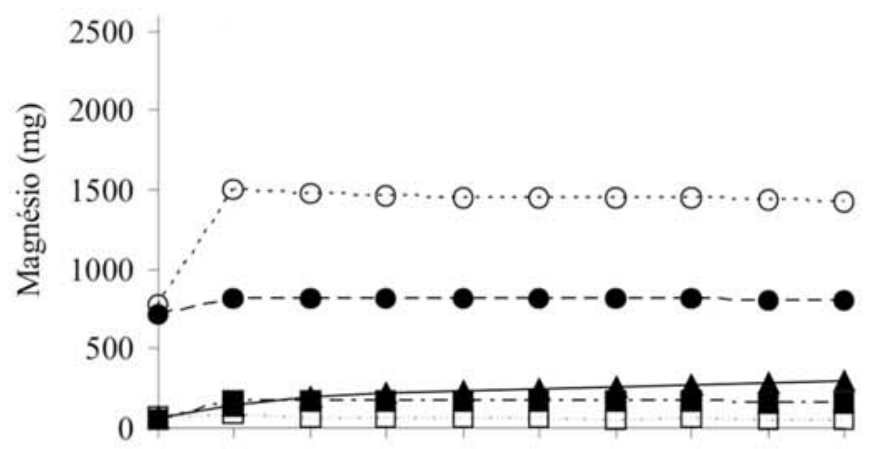

E.

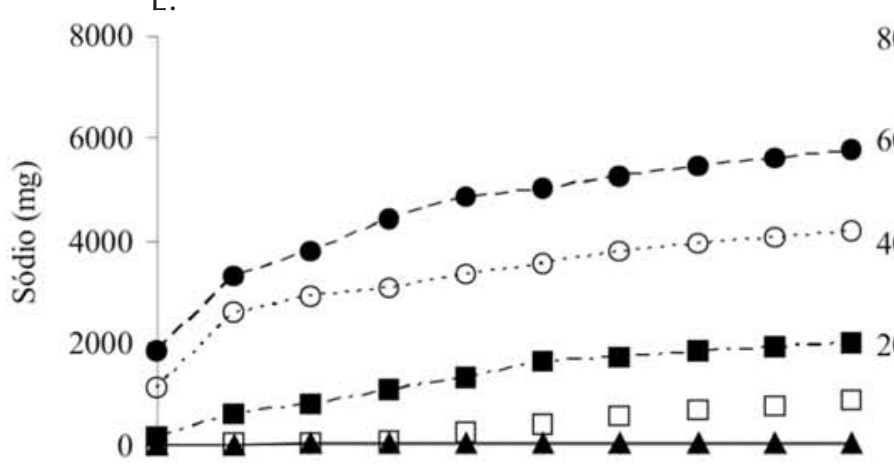

G.

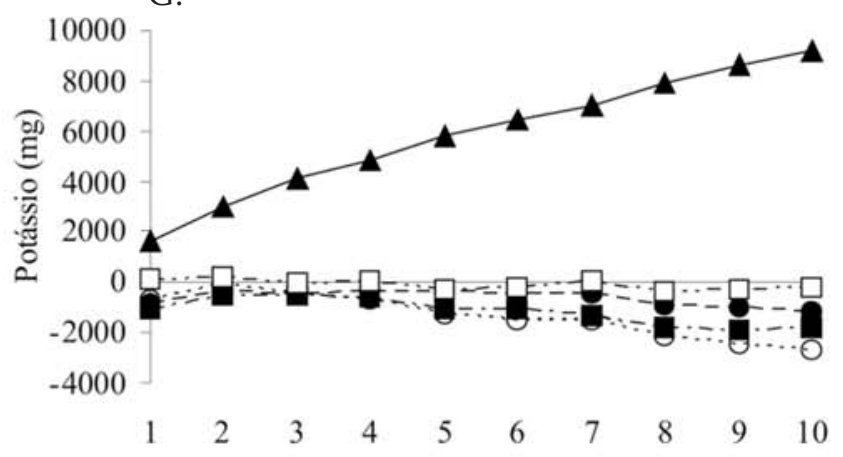

B.

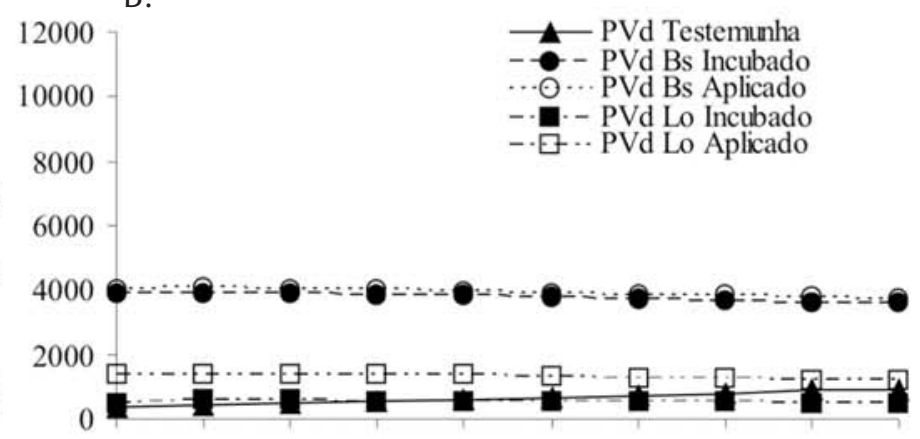

D.

2500

2000

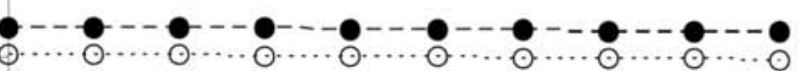

0

F.

8000

$6000-8000$

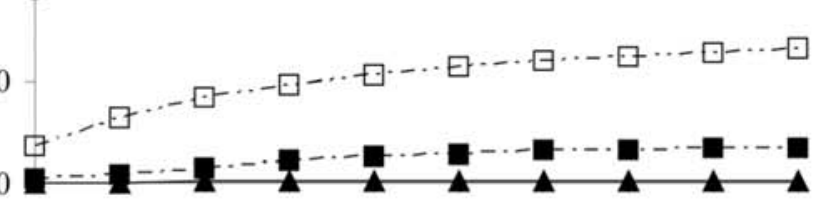

$\mathrm{H}$.

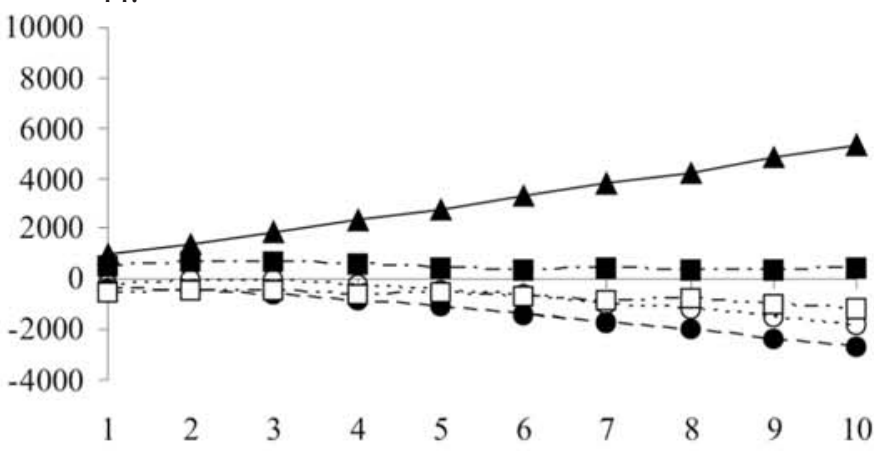

Coletas

Figura 2. Somatório da massa dos cátions lixiviados das colunas tratadas com 2 resíduos: Biossólido (Bs) e Lodo (Lo), nos dois solos utilizados, Nitossolo Vermelho distroférrico (NVdf) e Argissolo Vermelho distrófico (PVd), subtraídos dos tratamentos testemunhas 

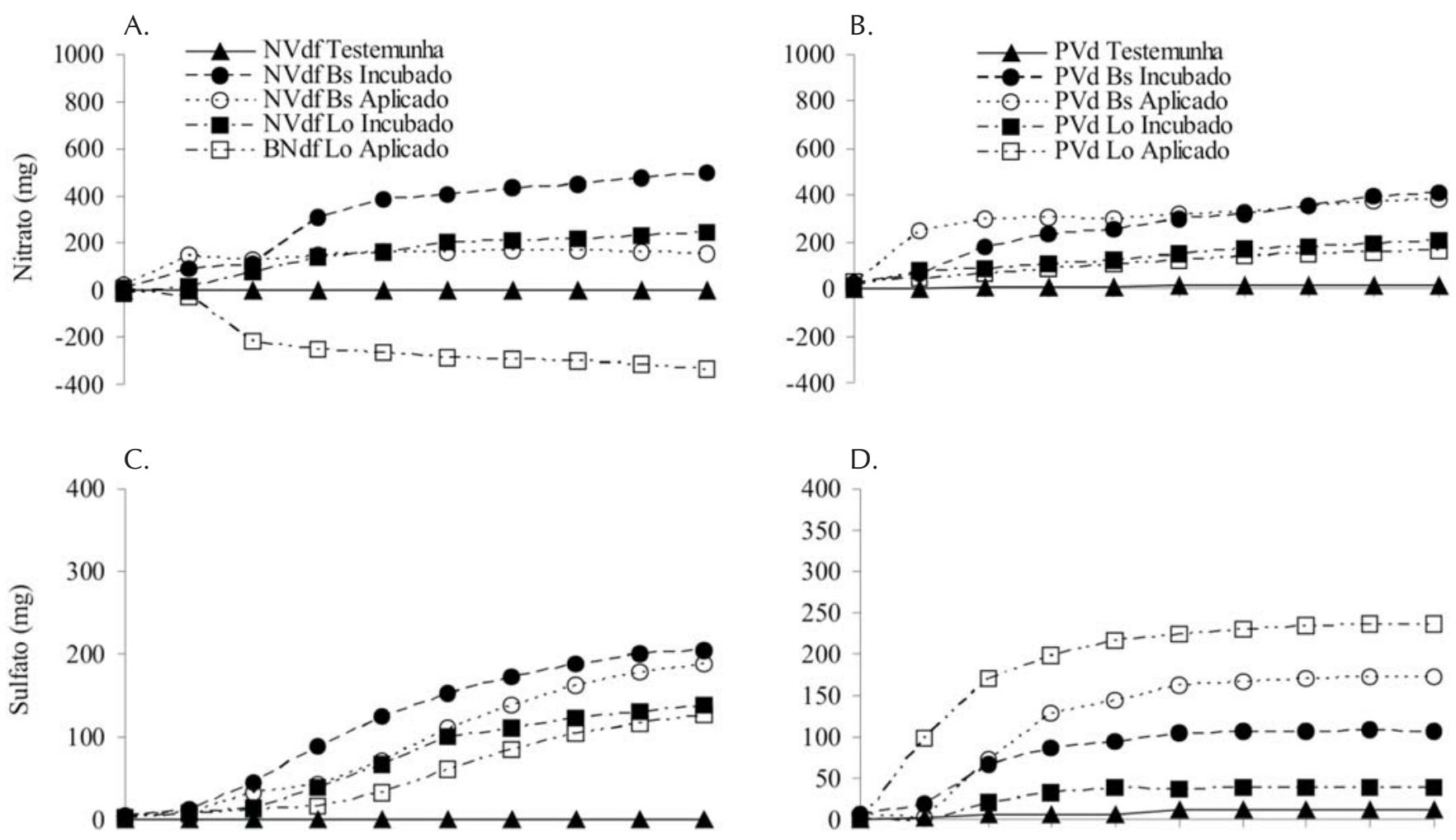

E.
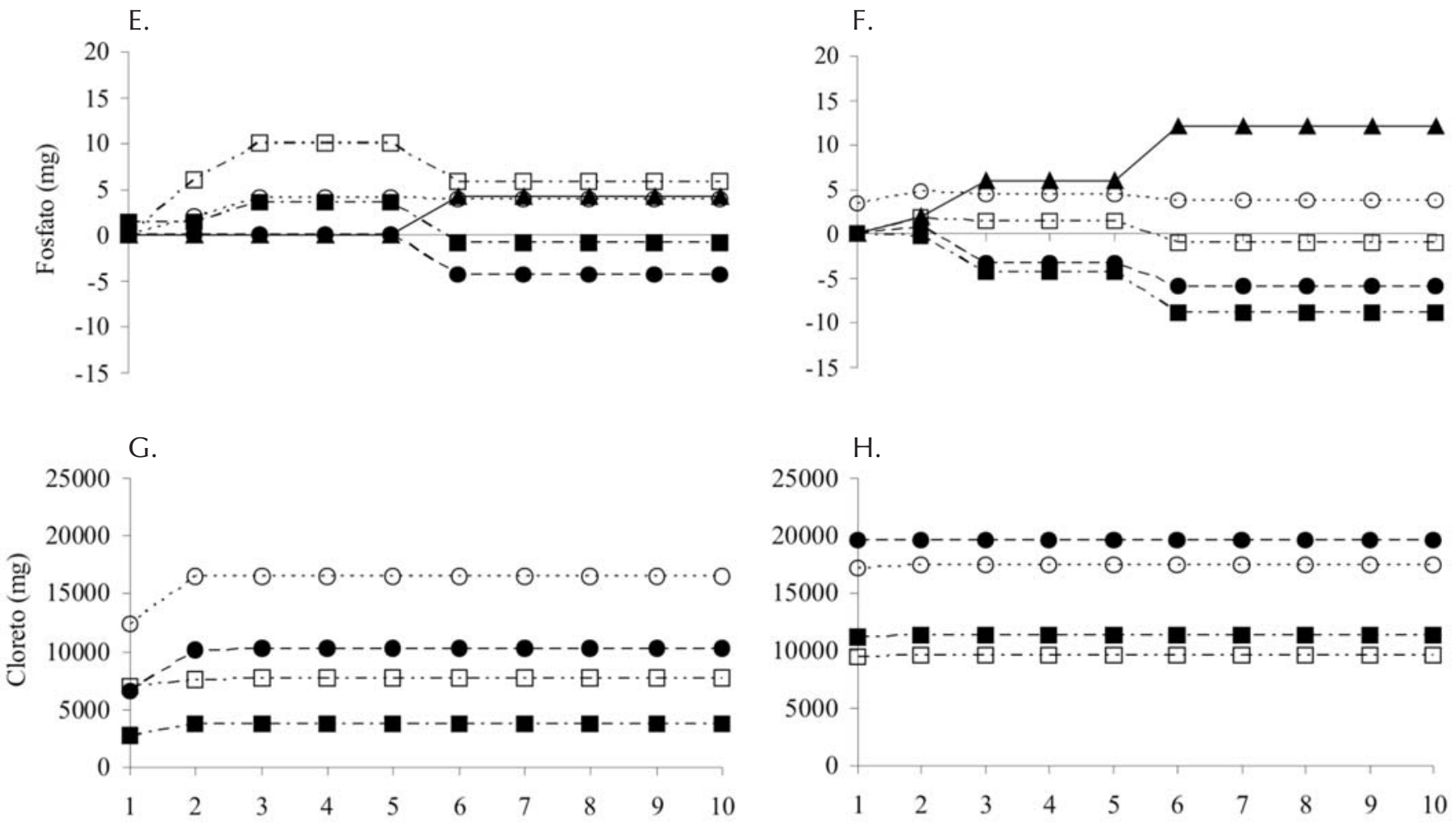

\section{Coletas}

Figura 3. Somatório das massa dos ânions lixiviados das colunas tratadas com 2 resíduos, Biossólido (Bs) e Lodo (Lo), nos dois solos utilizados, Nitossolo Vermelho distroférrico (NVdf) e Argissolo Vermelho distrófico (PVd), subtraídos dos tratamentos testemunha 
ter favorecido uma retirada maior do nitrogênio em solução pelos microrganismos apresentando, desta forma, a curva negativa (Figura 3A); este comportamento, apresentado somente pelo NVdf, se deve à maior quantidade de matéria orgânica (Tabela 3), associada a uma atividade biológica maior que, em contato com uma grande fonte de carbono, no caso a Lo, causou grande crescimento populacional necessitando, para tal, absorver nutrientes disponíveis na solução do solo.

A comparação das massas de $\mathrm{NO}_{3}{ }^{-}$lixiviado pelos solos mostra que o NVdf apresentou valores superiores e estatisticamente diferentes (81,35 mg), quando comparado ao PVd (38,24 mg), ( $<$ 0,05); no PVd, os tratamentos com resíduos exerceram diferença no $\mathrm{NO}_{3}{ }^{-}$lixiviado sendo que, na média, o Bs foi superior ao Lo e à testemunha. A diferença na lixiviação do $\mathrm{NO}_{3}{ }^{-}$, originário da decomposição dos resíduos aplicados, pode ser devido à matéria orgânica original dos solos. A matéria orgânica, quando em contato com os resíduos aplicados, tem sua mineralização favorecida, liberando $\mathrm{NO}_{3}^{-}$que, em concentrações maiores, pode mascarar o efeito dos tratamentos; o NVdf apresentou teor de matéria orgânica 2,36 vezes maior que o PVd (Tabela 3).

A lixiviação do sulfato apresentou, na maioria dos tratamentos, comportamento semelhante ao $\mathrm{NO}_{3}{ }^{-}$, isto é, este ânion mostrou-se com menor lixiviação com a aplicação dos dois primeiros pulsos de água (Figuras 3A, B, C e D) e atingiu $90 \%$ do total de sua lixiviação somente nos $8^{\circ}$ e $9^{\circ}$ pulsos, para os solos PVd e NVdf, respectivamente.

O sulfato apresentou lixiviação considerável a partir da terceira aplicação de água, não devendo ter formado par iônico com o $\mathrm{Ca}^{2+}$ e $\mathrm{Mg}^{2+}$, a exemplo do que ocorre em experimentos com gesso (Pavan, 1981) demonstrando que outro ânion acompanhou esses cátions na sua lixiviação.

Assim como o nitrogênio, o enxofre é utilizado pelos microrganismos durante o processo de decomposição de matéria orgânica; então, se existe maior consumo de $\mathrm{NO}_{3}{ }^{-}$ pelos microrganismos em um tratamento, também deve ocorrer maior consumo de $\mathrm{SO}_{4}{ }^{2-}$.

Os valores obtidos para $\mathrm{PO}_{4}{ }^{3-}$ no material lixiviado são extremamente baixos (Figuras $3 \mathrm{E}$ e F), indicando baixa movimentação deste ânion nos solos utilizados (Chen et al., 2003; Basso et al., 2005), os baixos teores de lixiviação do $\mathrm{PO}_{4}{ }^{2-}$ estão associados ao tipo de ligação que este íon forma com os óxidos e hidróxidos de ferro e alumínio, minerais da fração argila abundantes nos solos estudados, isto é, o $\mathrm{PO}_{4}{ }^{2-}$ forma complexos de esfera interna com esses minerais, e ligações covalentes com sua superfície (Sposito, 1989). A formação desses complexos resulta na baixa mobilidade do ânion, que pode ser considerada insignificante (Chen et al., 2003; Basso et al., 2005), já que a maior lixiviação constatada (Lo no PVd) correspondeu a apenas $1,3 \%$ do total de $\mathrm{PO}_{4}{ }^{2-}$ existente.

$\mathrm{O}$ ânion $\mathrm{Cl}^{-}$apresentou comportamento semelhante aos cátions $\mathrm{Ca}^{2+}$ e $\mathrm{Mg}^{2+}$, além de uma rápida lixiviação (Figuras 2A, B, C, D e Figuras 3G e H); no segundo pulso de água o ânion já havia lixiviado $100 \%$ do total no PVd e

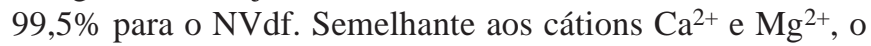
$\mathrm{Cl}^{-}$também não mostrou diferença estatística no total lixiviado entre os solos mas, comparando-se os resíduos, o Bs indicou valores de $\mathrm{Cl}^{-}$significantemente superiores ao Lo (p < 0,05), 2080,54 e 1293,86 mg de $\mathrm{Cl}^{-}$, respectivamente. Como a movimentação de íons no solo é realizada em pares iônicos, o $\mathrm{Cl}^{-}$deve ter sido o ânion que, preferencialmente, acompanhou os cátions $\left(\mathrm{Ca}^{2+}, \mathrm{Mg}^{2+}, \mathrm{Na}^{+}\right.$e $\left.\mathrm{K}^{+}\right)$pelo solo, sobretudo nos dois primeiros pulsos de água aplicada.

\section{Balanço final da lixiviação dos íons}

Verifica-se, no gráfico de correlação entre o balanço total de cargas associadas à lixiviação dos cátions e dos ânions, e os valores de CE, obtidos durante o período de coleta de dados do experimento (Figura 4), que a maior parte dos íons lixiviados foi avaliada $(r=0,92 ; \mathrm{p}<0,01)$; isto pode ser comprovado observando-se que o valor do coeficiente linear da equação de regressão $(19,81)$ é muito pequeno.

Analisando-se a adição via aplicação dos resíduos e sua lixiviação, observa-se que, para os cátions, o $\mathrm{Na}^{+}$ficou mais retido nas colunas já que os demais apresentaram, de forma geral, uma lixiviação maior que os teores aplicados chegando a apresentar, em alguns tratamentos, valores 3 vezes maiores no lixiviado em relação ao aplicado (Tabela 4).

A diferença entre os teores de $\mathrm{Ca}^{2+}$ e $\mathrm{Mg}^{2+}$ lixiviado e aplicados indica que estes foram removidos do solo; a remoção está associada à aplicação de grandes quantidades de $\mathrm{Na}^{+}$ que proporcionalmente favoreceu sua permanência no complexo de troca deslocando os outros cátions presentes no sistema, sobretudo $\mathrm{Ca}^{2+}$ e $\mathrm{Mg}^{2+}$.

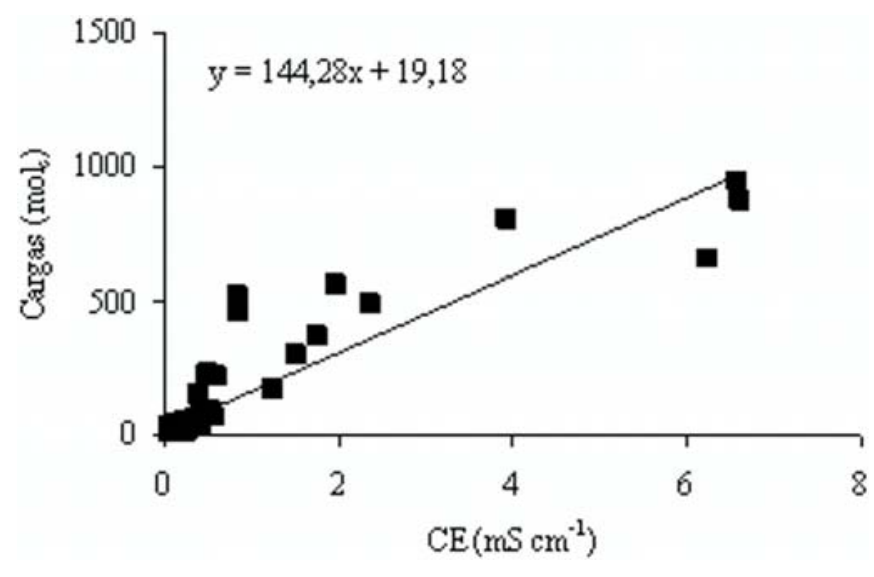

Figura 4. Correlação de Pearson (r) no nível de 1\% entre a condutividade elétrica $(C E)$ e o somatório das cargas elétricas dos íons das soluções percoladas, em todos os tratamentos realizados

Tabela 4. Balanço dos íons adicionados com os resíduos, Bs e Lo, e lixiviados

\begin{tabular}{lrrrrrrrr}
\hline \multirow{2}{*}{ Tratamento } & $\mathbf{C a}^{+2}$ & $\mathbf{M g}^{+2}$ & $\mathbf{K}^{+}$ & $\mathbf{N a}^{+}$ & $\mathbf{C l}^{-}$ & $\mathbf{S O}_{4}{ }^{2-}$ & $\mathbf{P O}_{4}{ }^{3-}$ & $\mathbf{N O}_{3}{ }^{-}$ \\
\cline { 2 - 10 } NVdf Bs incubado & 221 & 202 & 105 & 36 & 205 & 142 & 0 & 24 \\
NVdf Bs aplicado & 304 & 319 & 85 & 26 & 283 & 133 & 0,5 & 17 \\
NVdf Lo incubado & 154 & 322 & 120 & 62 & 51 & 29 & 0,4 & 25 \\
NVdf Lo aplicado & 136 & 249 & 146 & 28 & 71 & 27 & 1,1 & 10 \\
PVd Bs incubado & 165 & 141 & 34 & 41 & 294 & 112 & 0,4 & 11 \\
PVd Bs aplicado & 170 & 109 & 47 & 37 & 267 & 150 & 0,9 & 11 \\
PVd Lo incubado & 98 & 116 & 94 & 22 & 79 & 21 & 0,4 & 9 \\
PVd Lo aplicado & 145 & 176 & 68 & 81 & 69 & 51 & 1,3 & 8 \\
Média & 174 & 204 & 80 & 42 & 165 & 83 & 0,6 & 14 \\
\hline
\end{tabular}


Como o resíduo Lo adicionou menos $\mathrm{Ca}^{2+}, \mathrm{Mg}^{2+}$ e $\mathrm{Na}^{+}$ nas colunas foi menor a necessidade da lixiviação do $\mathrm{Cl}^{-}$para acompanhar os cátions, isto é, o resíduo Lo, embora apresentasse a maior concentração de $\mathrm{Cl}^{-}$na sua constituição, teve a maior parte deste ânion retida nos colóides do solo.

Semelhante ao $\mathrm{Cl}^{-}$, o resíduo Lo não apenas possui maiores valores de $\mathrm{SO}_{4}{ }^{2-}$ (Tabela 3 ) mas também foi retido pelo solo (Tabela 4), apresentando uma lixiviação menor que a adição; no entanto, o enxofre está diretamente ligado à atividade biológica e como o resíduo Lo apresenta carga orgânica maior, no processo de decomposição promove uma retenção maior do ânion pelos microrganismos.

$\mathrm{O}$ íon $\mathrm{NO}_{3}{ }^{-}$apresentou valores relativamente baixos no lixiviado quando comparados com as quantidades aplicadas (Tabela 4). A lixiviação inferior a $25 \%$ do total de nitrogênio aplicado deve estar relacionada a dois processos: i - à decomposição dos resíduos orgânicos que promove a incorporação de parte do $\mathrm{N}$ aplicado aos microrganismos; ii - à possível volatilização de parte do $\mathrm{N}$ aplicado na forma de $\mathrm{NH}_{3(\mathrm{~g})}$ (Stevenson, 1994).

\section{CONCLUSÕES}

1. A aplicação do resíduo biossólido (Bs) promoveu uma quantidade maior de elementos lixiviados quando comparado ao lodo (Lo).

2. A diferença de textura entre os solos, embora tenha promovido variações no processo de lixiviação dos íons, não teve efeito decisivo devido à alta dosagem aplicada dos resíduos e à manutenção da alta umidade no interior das colunas.

3. Os íons avaliados apresentaram comportamentos distintos; aqueles que formam complexos de esfera externa $\left(\mathrm{NO}_{3}{ }^{-}\right.$, $\mathrm{Cl}^{-}, \mathrm{Ca}^{2+}, \mathrm{Mg}^{2+}$ e $\mathrm{Na}^{+}$) tiveram rápida lixiviação e mostraram maior potencial de poluição de águas subterrâneas, enquanto os íons que formam complexos de esfera interna se comportaram diferentemente, sendo que o $\mathrm{PO}_{4}{ }^{3-}$ indicou baixa lixiviação, o $\mathrm{K}^{+}$lixiviou menos que nos tratamentos testemunhas e o $\mathrm{SO}_{4}{ }^{2-}$ lixiviou mais a partir da $3^{\mathrm{a}}$ coleta.

\section{AGRADECIMENTOS}

Ao Conselho Nacional de Desenvolvimento Científico e Tecnológico (CNPq), pela bolsa concedida.

\section{LITERATURA CITADA}

Agassi, M.; Kirsten, W. F. A.; Loock, A. H.; Fine, P. Percolation and leachete composition in a disturbed soil layer mulched with sewage biosolids. Soil \& Tillage Research, v.45, p. 359-372, 1998.

Amaral, A. S.; Anghinoni, I.; Hinrichs, R.; Bertol, I. Movimentação de partículas de calcário no perfil de um cambissolo em plantio direto. Revista Brasileira de Ciência do Solo, v.28, p.359-367, 2004.
Assadi, M. E.; Clemente, R. S.; Gupta, A. D.; Loof, R.; Hansen, K. G. Impacts of fertigation via sprinkler irrigation on nitrate leaching and corn yield in an acid-sulphate soil in Thailand. Agricultural Water Management, v.52, p.197-213, 2002.

Basso, C. J.; Ceretta, C. A.; Durigon, R.; Poletto, N.; Girotto, E. Dejeto líquido de suínos: II-perdas de nitrogênio e fósforo por percolação no solo sob plantio direto. Ciência Rural, v.35, n.6, p.1305-1312, 2005.

Benito, Y.; Ruiz, M.; Cosmem, P.; Merino, J. L. Study of leaches obtained from the disposal of fly ash from PFBC and AFBC processes. Chemical Engineering Journal, v.84, p.167-171, 2001.

Brady, N. C. Natureza e propriedades do solo. 7.ed. Rio de Janeiro: Freitas Bastos, 1989, 878p.

Chen, Y. X.; Zhu, G. W.; Tian, G. M.; Chen, H. L. Phosphorus and copper leaching from dredged sediment applied on a sandy loam soil: Column study. Chemosphere, v.53, p.1179-1187, 2003

Cheung, N. S.; Venkitachalam, T. H. Assessment of contamination by percolation of septic tank effluent through natural and amended soils. Enviromental Geochemistry and Healt, v.26, n.2, p.157-168, 2004.

Coelho, F. C; Ruiz, H. A.; Ferreira, P. A.; França, G. E., de; Araujo, C. A. de S.; Duarte, M. A. Transporte do amônio em colunas com agregados de um Latossolo Vermelho distrófico. Revista Brasileira de Engenharia Agrícola e Ambiental, v.4, n.3, p.362-367, 2000.

Costa, S. N. da; Mauro, A. M.; de Matos, A. T.; Ramos, V. B. N. Mobilidade de nitrato em colunas de solo sob condições de escoamento não permanente. Revista Brasileira de Engenharia Agrícola e Ambiental, v.3, n.2, p.190-194, 1999.

Cooke, C. M.; Gove, L.; Nicholson, F. A.; Cook, H. F.; Beck, A. J. Effect of drying and composting biosolids on movement of nitrate and phosphate through repacked soil columns under steady-state hydrological conditions, Chemosphere, v.44, p.757-804, 2001.

EMBRAPA. Empresa Brasileira de Pesqwuisa Agropecuária. Serviço Nacional de Levantamento e Conservação de Solos. Manual de métodos e análises de solos. 2.ed. Rio de Janeiro: EMBRAPA, 1997, 212p.

Ernani, P. R.; Ribeiro, M. S.; Bayer, C. Modificações químicas em solos ácidos ocasionadas pelo método de aplicação de corretivos da acidez e de gesso agrícola. Scientia Agrícola, v.58, n.4, p.825-831, 2001.

Hansen, B.; Kristensen, E. S.; Grant, R.; Høgh-Jensen, H.; Simmelsgaard, S. E.; Olesen, J. E. Nitrogen leaching from conventional versus organic farming systems - a systems modeling approach. European Journal of Agronomy, v.13, p.65-82, 2000.

Iwai, C. K. Tratamento de chorume através de percolação em solos empregados como material de cobertura de aterros para resíduos sólidos urbanos. Bauru: UNESP. 2005. 205p. Dissertação Mestrado

Jang, Y. C.; Townsend, T. Sulfate leaching from recovered construction and demolition debris fines. Advances in Environmental Research, v.5, n.3, p.203-217, 2001.

Ludwig, B.; Kölbl, A. Modelling cation exchange in columns of disturbed and undisturbed subsoil. European Journal of Soil Science, v.53, p.645-653, 2002.

Malavolta, E.; Vitti, G. C; de Oliveira, S. A. Avaliação do estado nutricional das plantas: princípios e aplicações. Piracicaba: Potafós, 1997. 319p. 
Mortensen, J.; Nielsen, K. H.; Jørgensen, U. Nitrate leaching during establishment of willow (Salix viminalis) on two soil types and at two fertilization levels. Great Britain, Biomass and Bioenergy, v.15, n.6, p.457-466, 1998.

Nascimento, C. W. A.; Barros, D. A. S.; Melo, E. E. C., Oliveira, A. B. Alterações químicas em solos e crescimento de milho e feijoeiro após aplicação de lodo de esgoto. Revista Brasileira de Ciência do Solo, v.28, 385-392, 2004.

Pavan. M. A. Toxicity of Al(III) to coffee (Coffea Arabica L.) in nutrient solution cuture and in oxisols and ultisols amended with $\mathrm{CaCO}_{3}, \mathrm{MgCO}_{3}$, and $\mathrm{CaSO}_{4} \cdot 2 \mathrm{H}_{2} \mathrm{O}$. California: University of California Riverside, 1981. 214p. Tese Doutorado

SAS. SAS User's Guide. SAS Institute, Inc., Cary, NC. 2001

Shuman, L. M. Phosphorus and nitrate nitrogen in runoff following fertilizer application to turfgrass. Journal of Environmental Quality, v.31, p.1710-1715, 2002.

Silva, J. da; Silva, P. S. L. e; de Oliveira, M.; Silva, K. M. B. e. Efeito de esterco bovino sobre os rendimentos de espigas verdes e de grãos de milho. Horticultura Brasileira, v.22, n.2, p. 326-331, 2004.

Silva, R. L. B.; Barra, C. M.; Monteiro, T. C. do N.; Brolhante, M. O. Estudo da contaminação de poços rasos por combustíveis orgânicos e possíveis conseqüências para a saúde pública no Município de Itaguaí, Rio de Janeiro, Brasil. Caderno de Saúde Pública, v.18, n.6, p.1599-1607, 2002.
Sisinno, C. L. S. Disposição em aterros controlados de resíduos sólidos industriais não-inertes: Avaliação dos componentes tóxicos e implicações para o ambiente e para a saúde humana. Caderno de Saúde Pública, v.19, n.2, p.369-374, 2003.

Sisinno, C. L. S.; Moreira, J. C. Avaliação da contaminação e poluição ambiental na área de influência do aterro controlado do Morro do Céu, Niterói, Brasil. Caderno de Saúde Pública, v.12, n.4, p.515-523, 1996.

Souza Júnior, I. G. de. Contribuição dos minerais de argila expansíveis na área superficial específica e na fixação de potássio em solos da bacia do rio Paraná. Maringá: UEM, 2001, 93p. Dissertação Mestrado

Sposito, G. The chemistry of soils. 1.ed. Oxford: Oxford University Press, 1989, 277p.

Stevenson F. J. Humus chemistry. genesis, composition, reactions. Second Edition, NewYork-Chichster-Brisbane-TorontoSingapore: John Wiley \& Sons, 1994, 530p.

Sutton, A. L. Effects of injection and surface applications of liquid swine manure on corn yeld and soil composition. Journal of Environmental Quality, v.11, n.2, p.468 - 472, 1982.

Warman, P. R., Effects of fertilizrer, pig manure and sewage sludge on timothy and soil. Journal of Environmental Quality, v.15, n.1, p.95-100, 1986. 